\title{
Place of Death and Density of Homecare Resources: A Nationwide Study in
} Japan

\author{
Takaaki Ikeda ${ }^{1,2}$, Toru Tsuboya ${ }^{2,3}$ \\ ${ }^{1}$ Department of Health Policy Science, Graduate School of Medical Science, Yamagata University, Yamagata, Japan \\ ${ }^{2}$ Department of International and Community Oral Health, Tohoku University Graduate School of Dentistry, Sendai, Japan \\ ${ }^{3}$ Department of Community Health, Public Health Institute, Shiwa, Japan
}

\section{Corresponding Author:}

Toru Tsuboya, $\mathrm{MD}, \mathrm{PhD}$

Department of International and

Community Oral Health, Tohoku

University Graduate School of

Dentistry, Sendai, 4-1, Seiryo-machi,

Aoba-ku, Sendai, Miyagi 980-8575,

Japan

E-mail: tsubo828@med.tohoku.ac.jp ORCID:

https://orcid.org/0000-0001-7741-0751

Received: January 7, 2021

Revised: March 1, 2021

Accepted: March 1, 2021

This study was presented a subset of the results at the IAGG Asia/Oceania

Regional Congress in Taipei in 2019.
Background: Although more than half of the population of Japan wants to spend their last days at home, approximately only $10 \%$ are able to do so. This study examined the associations between death at home and healthcare facility density by municipality based on the analysis of nationwide observed data in Japan. Methods: We used data on deaths at home and healthcare resources in municipalities across Japan for the fiscal years 2014 and 2017. The proportions of deaths at home by municipality were used as the dependent variable, while healthcare resources (e.g., hospital density) divided by the population of older people in each municipality and municipality-level income were used as independent variables. We applied a fixed-effects regression analysis to examine the association of healthcare resources and municipality-level income with death at home. Results: Clinics providing home medical care and facilities providing visiting nursing services were positively associated with death at home, with coefficients (95\% confidence intervals) of 2.14 (1.12 to 3.15 ) and 2.19 (0.99 to 3.39 ), respectively. Stratified analysis showed that these associations were observed in higher income-level municipalities but not in lower income-level municipalities. Conclusion: Municipalities with a higher density of home care services had higher rates of death at home, whereas municipalities with a higher density of hospitals had lower rates. We recommend the development of policy that allows hospitals to be converted into home care providers so that more people can spend time in peace at home at the end of their lives.

Key Words: Area-level income, Home medical care, Socioeconomic status, Visiting nursing services

\section{INTRODUCTION}

Many people wish to choose their place of death (POD). Most people in high-income countries have a desire to die outside hospitals, that is, at home or in a care home, if their disease situation is difficult to cure. According to a national report, more than half of Japanese people stated they would prefer to die at home; ${ }^{1,2)}$ however, it is not an easy task to ensure that one does. The government report in 2018 estimated that $72 \%$ of Japanese deaths occurred in hospitals. ${ }^{3)}$ In the United States, however, the percentage of deaths at home is on the rise, surpassing hospitals as the number one POD in 2017.) The reason many people want to spend their last days at home is to have a good death. A "good death" has a variety of components, such as a particular death process, a pain-free death, religious and spiritual needs met, emotional well-being, completion of life, treatment preferences, dignity, family, and quality of life. ${ }^{5)}$ The quality of death at home is reported to be better than that in palliative care units or hospitals. ${ }^{6}$ Without appropriate arrangements for end-of-life care, people often end up being transferred to subacute or acute care settings before death and experi- 
ence lower-quality terminal care. ${ }^{7,8)}$

In Japan, home healthcare has become more widespread since 2006 when the insurance system first included home healthcare support clinics. ${ }^{9)}$ Since then, the Japanese government has been fine tuning the medical fee system, revising it every 2 years to reward medical institutions that provide end-of-life care at home and increasing incentives for medical institutions that provide end-oflife care at home around the clock. This policy is based on the government's vision of a "Community-based Integrated Care System," which aims to ensure the comprehensive provision of healthcare, preventive care, nursing care, and housing in each community by $2025 .^{10)}$ The prefectural government is responsible for the medical care delivery system, while the municipal government is responsible for the long-term care delivery system, which are linked to achieve the government's vision. ${ }^{10,11)}$ Therefore, it is important to better understand how more people can achieve a death in their chosen location, which in most cases, is at home.

Previous studies have reported factors affecting POD. Besides people's wishes concerning their POD, medical factors, including symptom control, ${ }^{12)}$ availability of multidisciplinary home palliative care ${ }^{13)}$ or home care support medical service, ${ }^{14)}$ and cancer as opposed to other diagnoses, ${ }^{4)}$ also influence whether or not people can end their lives at home. Additional to medical factors are social factors, such as living alone, ${ }^{15)}$ having caregiver support ${ }^{16)}$ and caregivers' coping skills or educational attainment. ${ }^{17)}$ Although some studies have evaluated factors affecting POD, they have limitations. For instance, some studies evaluated only individual-level factors associated with POD, ${ }^{18-21)}$ and information on area-level factors that affect POD remains largely unexplored. ${ }^{22)}$

One example of area-level factors is the income level of the area. People living in the poorest communities may be more likely to die in hospitals than people living in affluent neighborhoods in high-income countries. ${ }^{17)}$ Only one cross-sectional study from Japan using nationwide data reported an association between higher municipality-level income and higher rates of death at home. ${ }^{14)}$ However, this study was a cross-sectional study, and it remains unclear whether area-level income is associated with POD. In many countries, there is a large gap between people's wishes and where they eventually die. It is natural to assume that local healthcare resources affect the POD. One Japanese cross-sectional study reported a positive association between the density of home visiting clinics and higher rates of death at home; however, the authors ${ }^{14)} \mathrm{did}$ not consider local healthcare resources such as home-visit nursing offices. In Japan and other countries, the densities of home-visiting clinics or nursing offices vary across municipalities or prefectures. While these considerable differences in local healthcare resources are assumed to affect POD, no quantitative studies have analyzed this association. We hypothesized that local healthcare resources such as the density of clinics, hospitals, home-visiting nursing offices, and different types of care facilities would affect people's choice of POD. Thus, this study examined the association between the percentages of deaths at home and the density of home-visiting medical care services by municipality using nationwide public data in Japan.

\section{MATERIALS AND METHODS}

\section{Data}

We used public data provided by the Ministry of Health, Labour and Welfare on deaths at home and healthcare resources (e.g., hospital density) across all 1,741 municipalities. ${ }^{23)}$ Data from the fiscal years (FYs) of 2014 and 2017 were used. We constructed twowave panel data. No ethical approval was obtained as we used only publicly available data.

\section{Variables}

We defined the proportion of deaths at home by municipality as the dependent variable. The POD in Japan is recorded on a physician-written death certificate. We defined the densities of the following healthcare resources as independent variables: (1) clinics, (2) hospitals, (3) home care support hospitals, (4) home care support clinics, (5) hospitals providing home visit medical care, (6) clinics providing home visit medical care, (7) hospitals/clinics/nursing stations providing home-visit nursing care, (8) longterm care hospital beds, (9) long-term healthcare facility beds, (10) rooms in special nursing homes for older adults, (11) smallscale multifunction home care offices, and (12) composite service offices. Home care support hospitals/clinics (\#3/\#4) were defined as those that specialized in 24-hour home care support and were approved by the government based on facility requirements. ${ }^{24)}$ In Japan, clinics and hospitals are defined as those with $\leq 20$ and $>20$ beds, respectively. The requirement for home care support hospitals/clinics involves attending physicians or nurses to maintain a system that allows 24-hour contact with patients and their families and cooperating with local long-term care and welfare service providers. More details on the requirement are described elsewhere. ${ }^{24)}$ Other hospitals/home clinics not approved but providing home visit medical care were categorized into variables listed in \#5 or \#6. Composite service offices (\#12) were defined as those providing home-visit nursing care in addition to care services offered by small-scale multifunction-type home care offices. In Japan, more than $90 \%$ of deaths occurred in people aged 65 years and older in $2017{ }^{25)}$ Moreover, many users of the healthcare resource used in our analysis were older people. Thus, all the variables were includ- 
ed in the analytic models after being divided by the population of the older residents in each municipality (shown as "per 1,000 of the municipality-level population" in the tables). Data on municipality-level income (per capita income of the municipality) in each FY were obtained from the Ministry of Internal Affairs and Communications. ${ }^{26)}$

\section{Statistical Analysis}

We used a fixed-effects regression model with robust standard errors to examine the associations between healthcare resources and municipality-level income and deaths at home. This model estimated within-municipality changes in the proportions of deaths at home (dependent variable) regressed on changes in the independent variables described above. We developed a multivariate model that included all independent variables (Model 1). We then constructed a second model that added an interaction term between municipality-level income and significant variables to confirm whether the effect of healthcare resources on death at home differed by income level (Model 2). The municipality-level income variable used in the interaction term was dichotomized according to income data from 2014. We also performed a stratified analysis according to income level in 2014. All analyses were conducted using Stata version 16.0 (Stata Corp, College Station, TX).

\section{RESULTS}

The proportions of deaths at home in each prefecture according to the year of investigation are presented in Table 1 . Overall, the average proportion of deaths at home in Japan increased slightly from $12.8 \%$ in 2014 to $13.2 \%$ in 2017. Among the 47 prefectures, the proportion of deaths at home increased the most in Tokyo, by 4.6\% from 2014 to 2017 (Table 1). Table 2 shows the changes in the area-level factors between 2014 and 2017.

The results of the multivariate fixed-effects regression models are shown in Table 3. Our regression models showed that death at home was positively associated with the density of clinics providing home visit medical care and hospitals/clinics/nursing stations/nurse stations providing home-visit nursing care, with coefficients (95\% confidence intervals [CIs]) of 2.14 (1.12 to 3.15) and 2.19 (0.99 to 3.39), respectively. The densities of hospitals, long-term care hospital beds, long-term healthcare facilities, and small-scale multifunction-type home care offices were inversely associated with death at home (Model 1). For instance, the density of hospitals was negatively associated with death at home with a coefficient $(95 \% \mathrm{CI})$ of -3.93 ( -7.45 to -0.40$)$. Although area-level income was not associated with death at home, several interaction terms of income level in 2014 with the density of healthcare resources (hospitals/clinics/nursing stations providing home-visit nursing guidance, long-term healthcare facilities, and small-scale multifunction home care offices) were significant (Model 2).

Table 4 shows our stratified analysis by municipality income level in 2014. In higher-income municipalities, the densities of home care support clinics, clinics providing home visit medical care, and hospitals/clinics/nursing stations providing home-visit nursing and guidance were positively associated with death at home. However, these associations were not observed in lower income municipalities. In contrast, the density of hospitals was negatively associated with death at home in lower-income municipalities but not in higher-income municipalities.

\section{DISCUSSION}

Using comprehensive empirical data on Japanese municipalities, we showed a significant positive association between the rates of death at home and the density of clinics providing home-visit medical care. In addition, the density of facilities providing nursing services was positively associated with death at home. Conversely, the density of hospitals or long-term care facilities, as well as non-medical care facilities, was negatively associated with home death.

The main finding of our study was the positive association between death at home and the density of clinics providing home visit medical care, which is consistent with that of a previous study. ${ }^{14)}$ We further added robust evidence using two-wave panel data that higher hospital bed density may lead to a lower death rate at home. ${ }^{14)}$ We observed a significant association between death at home and home care support clinics but not home care support hospitals. This discordance might be explained by the differences in the roles of these two facilities (clinics or hospitals). Medical care at clinics is often repetitive and medium to long term; thus, it is relatively easy to form a trusting relationship between patients and their doctor. Older people who do not seek life-saving care using advanced medical equipment may particularly want to be cared for by a doctor they trust whom they see regularly. In contrast, When patients often visit the hospital, it is due to a sudden illness. Since it is their intial meeting, it is difficult for them to establish a trusting relationship. In particular, if the patient is an older person with a difficult medical condition, he or she may not want to spend the rest of their life in a hospital but rather desire to see his or her family doctor and return to the clinic from the hospital. ${ }^{24)}$ The results of our study also provide new evidence of the positive association between medical facilities or nursing offices that provide home nursing care and death at home. Another study from Japan also showed that the use of in-home services was associated with a 
Table 1. Proportions of home deaths with respect to prefecture and year of investigation

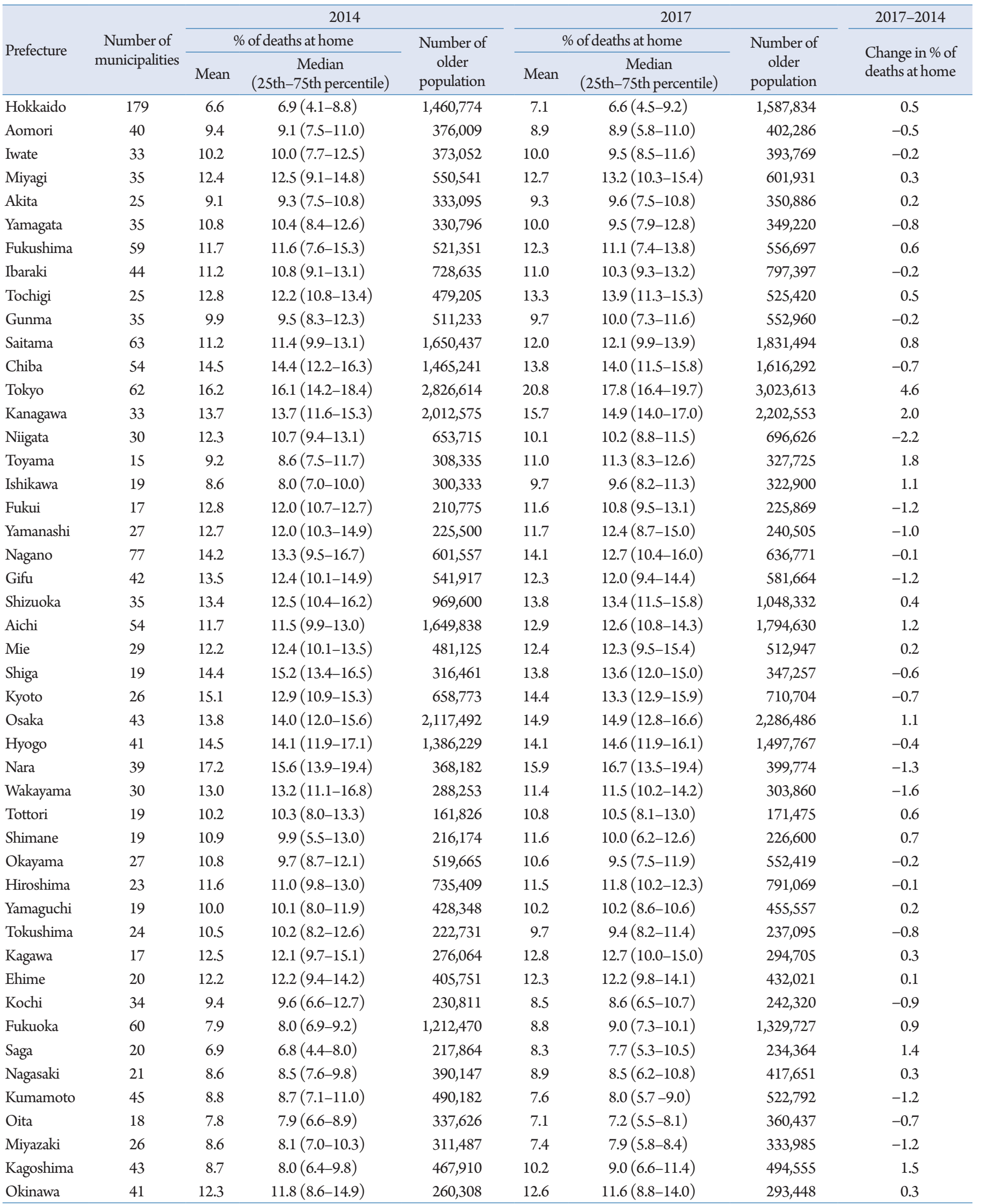


Table 2. Changes in area-level factors between 2014 and 2017

\begin{tabular}{|c|c|c|c|c|c|c|}
\hline & \multicolumn{3}{|c|}{ Non-standardized values } & \multicolumn{3}{|c|}{ Standardized values ${ }^{\text {a) }}$} \\
\hline & 2014 & 2017 & $\Delta 2017-2014$ & 2014 & 2017 & $\Delta 2017-2014$ \\
\hline Density of hospitals & $4.88 \pm 12.12$ & $4.83 \pm 11.99$ & -0.05 & $0.25 \pm 0.23$ & $0.23 \pm 0.21$ & -0.02 \\
\hline Density of clinics & $57.70 \pm 169.53$ & $58.28 \pm 172.58$ & 0.58 & $2.65 \pm 2.26$ & $2.50 \pm 2.22$ & -0.15 \\
\hline Density of home care support hospitals & $0.53 \pm 1.72$ & $0.69 \pm 2.13$ & 0.15 & $0.03 \pm 0.08$ & $0.03 \pm 0.08$ & 0.00 \\
\hline Density of home care support clinics & $8.27 \pm 28.66$ & $8.42 \pm 29.20$ & 0.15 & $0.34 \pm 0.37$ & $0.33 \pm 0.41$ & -0.01 \\
\hline $\begin{array}{l}\text { Density of hospitals providing home visit medi- } \\
\text { cal care }\end{array}$ & $1.55 \pm 3.52$ & $1.55 \pm 3.54$ & 0.01 & $0.10 \pm 0.16$ & $0.10 \pm 0.15$ & -0.01 \\
\hline $\begin{array}{l}\text { Density of clinics providing home visit medical } \\
\text { care }\end{array}$ & $11.83 \pm 34.28$ & $11.58 \pm 34.22$ & -0.25 & $0.60 \pm 0.53$ & $0.56 \pm 0.63$ & -0.04 \\
\hline $\begin{array}{l}\text { Density of hospitals/clinics/nursing stations } \\
\text { providing home-visit nursing and guidance }\end{array}$ & $1.65 \pm 6.93$ & $1.88 \pm 8.99$ & 0.23 & $0.43 \pm 0.41$ & $0.43 \pm 0.59$ & 0.00 \\
\hline Density of long-term care hospital beds & $38.44 \pm 121.20$ & $30.64 \pm 104.14$ & -7.80 & $2.02 \pm 5.78$ & $1.54 \pm 5.11$ & -0.48 \\
\hline Density of long-term healthcare facility beds & $208.03 \pm 478.91$ & $214.06 \pm 494.53$ & 6.03 & $12.55 \pm 13.99$ & $12.02 \pm 13.52$ & -0.54 \\
\hline $\begin{array}{l}\text { Density of rooms of special nursing homes for } \\
\text { older adults }\end{array}$ & $286.23 \pm 631.80$ & $311.60 \pm 701.29$ & 25.37 & $21.54 \pm 17.74$ & $21.71 \pm 17.74$ & 0.16 \\
\hline $\begin{array}{l}\text { Density of small-scale multifunction type home } \\
\text { care offices }\end{array}$ & $2.66 \pm 7.10$ & $3.07 \pm 8.21$ & 0.41 & $0.15 \pm 0.27$ & $0.16 \pm 0.28$ & 0.01 \\
\hline Density of composite service offices & $0.09 \pm 0.55$ & $0.22 \pm 0.95$ & 0.13 & $0.00 \pm 0.01$ & $0.01 \pm 0.02$ & 0.00 \\
\hline Municipality-level income (Japanese yen ${ }^{\mathrm{b})}$ ) & $2,778.35 \pm 552.82$ & $2,855.87 \pm 554.71$ & 77.52 & - & - & - \\
\hline
\end{tabular}

Values are presented as mean \pm standard deviation.

a) All healthcare resources other than municipality-level income were standardized by the number of the older population in each municipality per 1,000 municipality-level population. ${ }^{\text {b) }} 100$ yen roughly equals one US dollar.

higher probability of death at home. ${ }^{27)}$ Clinically, it is assumed that care at home is necessary for peaceful end-of-life care, and our analysis confirmed this assumption. Currently, although most people in Japan want to spend a peaceful end-of-life at home, this goal is not often achieved. To fill this gap, more facilities providing home visiting care are needed.

The densities of hospitals, long-term care hospital beds, and long-term care facilities in the area were negatively associated with home death rates, with a large coefficient $(95 \% \mathrm{CI})$ for hospitals of $-3.93(-7.45$ to -0.40$)$. The negative association between hospital density and death at home was reported previously, which is consistent with our finding. ${ }^{14)}$ Although the causal interpretation of our result using fixed-effects models might be questioned, it is reasonable to consider this as a causal relationship to some extent, justified by the concept of "physician-induced demand," in which a physician influences a patient's demand for care against the physician's interpretation of the best interests of the patient. ${ }^{28)}$ Almost $90 \%$ of hospitals in Japan are private; thus, physicians and other healthcare workers in hospitals might motivate patients to use their services unnecessarily so that their hospitals will not go bankrupt. An excess of hospital beds will not only increase healthcare costs but also negatively affect people's desire to die at home. In addition, Japan's population is likely to continue declining; therefore, the density of beds per population will increase. Given this situation, the Japanese government should work more aggressively to reduce the density of beds or provide incentives to become home care providers.

The associations between healthcare resources and death at home differed with respect to the area-level income. We observed a negative association between death at home and hospital density in lower-income municipalities but not in high-income municipalities. Hence, it was more difficult for people in deprived areas to spend their end-of-life at home than people in affluent areas. This finding is consistent with those of studies from the United States ${ }^{16,22)}$ and Japan. ${ }^{14)}$ Thus, disparities also exist in health and death. The co-payment for end-of-life care at home is relatively high compared to that at hospitalization, ${ }^{29)}$ although home care is covered by universal health insurance in Japan. The high cost of this co-payment likely influenced this choice. Our results emphasize the importance of addressing inequalities in access to home healthcare services.

While the present study has some significant findings, it has some limitations. First, a classification of "death at home" does not necessarily mean a comfortable peaceful death. It could include suicide, homicide, or unexpected sudden death such as myocardial infarction or stroke occurring at home. However, as the density of homicides and suicides was an order of magnitude lower than that of people accessing end-of-life care, this bias was unlikely to have significantly impacted our results. Second, this study examined only area-level factors. Future studies should consider both indi- 
Table 3. Area-level factors for deaths at home (multivariate fixed-effects regression analysis)

\begin{tabular}{|c|c|c|c|c|}
\hline & \multicolumn{2}{|c|}{ Model 1} & \multicolumn{2}{|c|}{ Model 2} \\
\hline & Coefficient & $95 \% \mathrm{CI}$ & Coefficient & $95 \% \mathrm{CI}$ \\
\hline \multicolumn{5}{|l|}{ Area-level factors for deaths at home } \\
\hline Density of hospitals & -3.93 & -7.45 to -0.40 & -7.30 & -13.17 to -1.44 \\
\hline Density of clinics & -1.31 & -2.89 to 0.28 & -0.76 & -2.38 to 0.85 \\
\hline Density of home care support hospitals & 0.50 & -3.63 to 4.63 & 1.01 & -2.79 to 4.82 \\
\hline Density of home care support clinics & 0.99 & -0.41 to 2.40 & 0.63 & -0.41 to 1.68 \\
\hline Density of hospitals providing home visit medical care & 1.76 & -0.85 to 4.37 & 1.81 & -0.78 to 4.40 \\
\hline Density of clinics providing home visit medical care & 2.14 & 1.12 to 3.15 & 1.11 & 0.17 to 2.06 \\
\hline $\begin{array}{l}\text { Density of hospitals/clinics/nursing stations providing home-visit nursing } \\
\text { and guidance }\end{array}$ & 2.19 & 0.99 to 3.39 & 3.99 & 2.84 to 5.15 \\
\hline Density of long-term care hospital beds & -0.16 & -0.24 to -0.08 & -0.21 & -0.30 to -0.12 \\
\hline Density of long-term healthcare facility beds & -0.10 & -0.19 to -0.01 & -0.09 & -0.21 to 0.04 \\
\hline Density of rooms of special nursing homes for older adults & 0.03 & -0.01 to 0.08 & 0.03 & -0.01 to 0.08 \\
\hline Density of small-scale multifunction type home care offices & -2.95 & -4.76 to -1.14 & -0.45 & -3.01 to 2.11 \\
\hline Density of composite service offices & 0.18 & -13.15 to 13.50 & 0.54 & -12.82 to 13.90 \\
\hline Municipality-level income (continuous) & 0.000 & -0.002 to 0.001 & -0.001 & -0.002 to 0.001 \\
\hline \multicolumn{5}{|l|}{ Interaction terms of municipality-level income in 2014 (ref. high-level income) } \\
\hline Density of hospitals & - & - & 4.36 & -2.04 to 10.76 \\
\hline Density of clinics providing home visit medical care & - & - & -0.12 & -1.80 to 1.55 \\
\hline $\begin{array}{l}\text { Density of hospitals/clinics/nursing stations providing home-visit nursing } \\
\text { and guidance }\end{array}$ & - & - & -4.56 & -6.15 to -2.97 \\
\hline Density of long-term care hospital beds & - & - & 0.23 & 0.08 to 0.38 \\
\hline Density of long-term healthcare facility beds & - & - & -0.02 & -0.19 to 0.15 \\
\hline Density of small-scale multifunction type home care offices & - & - & -3.69 & -6.71 to -0.67 \\
\hline
\end{tabular}

All healthcare resources other than municipality-level income were standardized by the number of the older population in each municipality per 1,000 municipality-level population.

Model 2 is additionally included interaction terms that were significantly associated in Model 1.

$\mathrm{CI}$, confidence interval.

Statistically significant associations $(\mathrm{p}<0.05)$ are indicated in bold type.

Table 4. Area-level factors for deaths at home with respect to income level in 2014 (multivariate fixed-effects regression analysis)

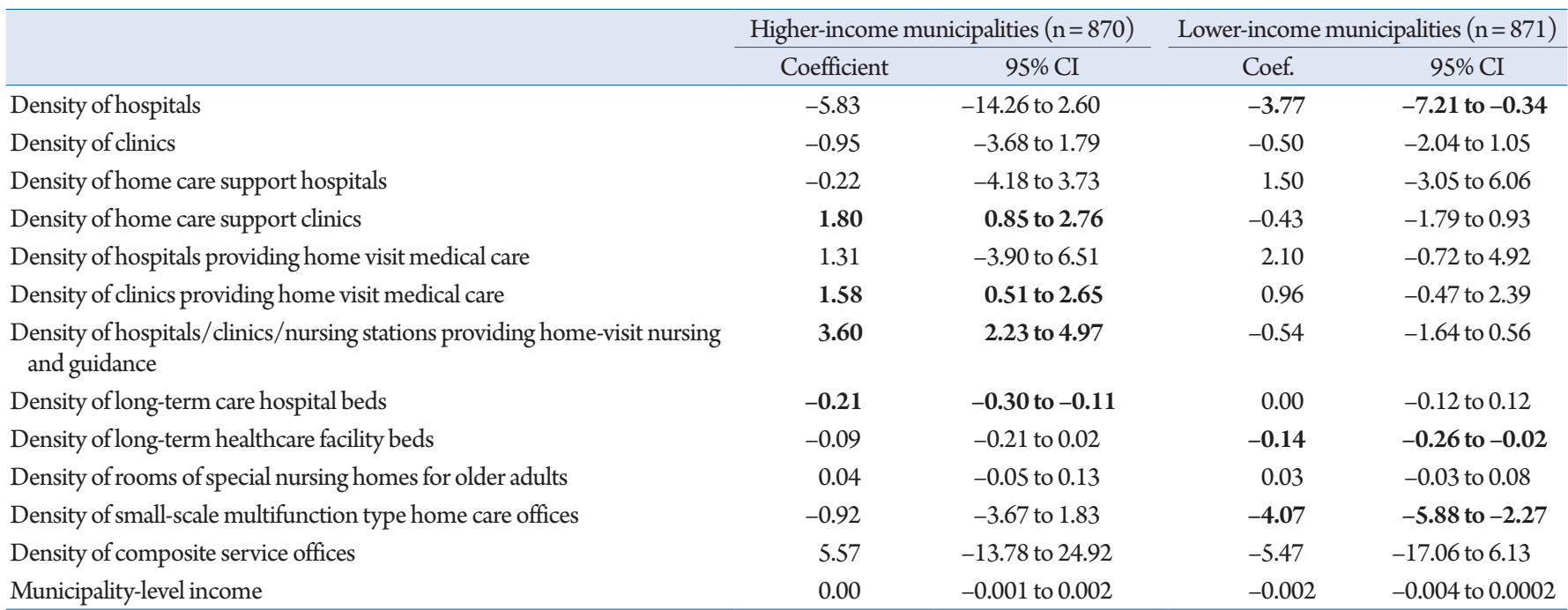

All healthcare resources other than municipality-level income were standardized by the number of older population in each municipality per 1,000 municipalitylevel population.

$\mathrm{CI}$, confidence interval.

Statistically significant associations $(\mathrm{p}<0.05)$ are indicated in bold type. 
vidual- and municipality-level factors. Third, our findings were based on observational data rather than data from randomized controlled trials. Thus, it was difficult to determine causal relationships. An abundance of local medical resources may allow many people to receive care at home; conversely, medical facilities supporting home care may exist in areas where many people receive care at home. Current research methods do not allow for a strict distinction between causes.

In conclusion, our analysis of comprehensive empirical data in Japan revealed a significant positive association between clinics supporting home medical care and death at home. Moreover, we found that the associations between healthcare resources and death at home differed with respect to area-level income. While most people in Japan want to spend their last days at home as much as possible, approximately only $10 \%$ achieve this goal. To close the regional gap in end-of-life care at home, the government should consider providing financial support for home healthcare in poor areas.

\section{ACKNOWLEDGEMENTS}

We thank Dr. Yoshimitsu Takahashi (Department of Health Informatics, Kyoto University School of Public Health, Kyoto), Dr. Hajime Yamazaki (Department of Healthcare Epidemiology, Kyoto University, Kyoto), Dr. Kemmyo Sugiyama (Tohoku University School of Dentistry), Dr. Yoko Ibuka (Faculty of Economics, Keio University, Tokyo), Dr. Kunio Tarasawa (Tohoku University School of Medicine) and Dr. Hatsuru Morita (Tohoku University School of Law) for their helpful discussion.

\section{CONFLICT OF INTEREST}

The researchers claim no conflicts of interest.

\section{FUNDING}

This research is financially supported by the Open Research Areas (ORA) program by Japan Society of Promotion of Science (INCARE). The funders had no role in study design, data collection and analysis, decision to publish, or preparation of the manuscript.

\section{AUTHOR CONTRIBUTION}

Conceptualization, TT, TI; Data curation, TT, TI; Writing-original draft, TT, TI; Writing-review \& editing, TT, TI.

\section{REFERENCES}

1. Cabinet Office Japan. Annual report on the ageing society 2019 [Internet]. Tokyo, Japan: Cabinet Office; 2019 [cited $2021 \mathrm{Mar}$
8]. Available from: https://www8.cao.go.jp/kourei/whitepaper/w-2019/html/zenbun/s1_3_1_4.html.

2. Ministry of Health, Labour and Welfare. Survey on attitudes toward medical care in the final stages of life [Internet]. Tokyo, Japan: Ministry of Health, Labour and Welfare; 2018 [cited 2021 Mar 8]. Available from: https://www.mhlw.go.jp/toukei/list/ dl/saisyuiryo_a_h29.pdf.

3. Portal Site of Official Statistics of Japan. Vital statistics [Internet]. Tokyo, Japan: Portal Site of Official Statistics of Japan; 2019 [cited 2021 Mar 8]. Available from: https://www.e-stat.go.jp/statsearch $/$ files? page $=1$ \&layout $=$ datalist $\&$ toukei $=00450011 \& \mathrm{t}-$ stat $=000001028897 \&$ cycle $=7 \&$ year $=20180 \&$ month $=0 \& \mathrm{t}-$ class $1=000001053058 \&$ tclass $2=000001053061 \& \mathrm{t}$ class $3=000001053065 \&$ result_back $=1$.

4. Cross SH, Warraich HJ. Changes in the place of death in the United States. N Engl J Med 2019;381:2369-70.

5. Meier EA, Gallegos JV, Thomas LP, Depp CA, Irwin SA, Jeste DV. Defining a Good death (successful dying): literature review and a call for research and public dialogue. Am J Geriatr Psychiatry 2016;24:261-71.

6. Kinoshita H, Maeda I, Morita T, Miyashita M, Yamagishi A, Shirahige $\mathrm{Y}$, et al. Place of death and the differences in patient quality of death and dying and caregiver burden. J Clin Oncol 2015;33: 357-63.

7. Nakamura S, Kuzuya M, Funaki Y, Matsui W, Ishiguro N. Factors influencing death at home in terminally ill cancer patients. Geriatr Gerontol Int 2010;10:154-60.

8. Gomes B, Higginson IJ. Factors influencing death at home in terminally ill patients with cancer: systematic review. BMJ 2006; 332:515-21.

9. Ministry of Health, Labour and Welfare. About home care support clinics [Internet]. Tokyo, Japan: Ministry of Health, Labour and Welfare; 2007 [cited 2021 Mar 8]. Available from: https:// www.mhlw.go.jp/shingi/2007/03/dl/s0312-11e_02.pdf.

10. Ministry of Health, Labour and Welfare. Guideline for regional healthcare vision [Internet]. Tokyo, Japan: Ministry of Health, Labour and Welfare; 2015 [cited 2021 Mar 8]. Available from: https://www.mhlw.go.jp/content/10800000/000711355.pdf.

11. Ministry of Health, Labour and Welfare. Community-oriented primary care [Internet]. Tokyo, Japan: Ministry of Health, Labour and Welfare; 2015 [cited $2021 \mathrm{Mar} 8$ ]. Available from: https:// www.mhlw.go.jp/stf/seisakunitsuite/bunya/0000080850.html.

12. Tang ST, McCorkle R. Determinants of place of death for terminal cancer patients. Cancer Invest 2001;19:165-80.

13. Costa V, Earle CC, Esplen MJ, Fowler R, Goldman R, Grossman $\mathrm{D}$, et al. The determinants of home and nursing home death: a systematic review and meta-analysis. BMC Palliat Care 2016; 
15:8.

14. Morioka N, Tomio J, Seto T, Yumoto Y, Ogata Y, Kobayashi Y. Association between local-level resources for home care and home deaths: a nationwide spatial analysis in Japan. PLoS One 2018;13:e201649.

15. Shim H, Kim S, Kim M, Kim BS, Jeong E, Lee YJ, et al. Older men living with spouse and older women living with spouse and children have lower frailty prevalence: the Korean Frailty and Aging Cohort Study (KFACS). Ann Geriatr Med Res 2020;24: 204-10.

16. Grande GE, Addington-Hall JM, Todd CJ. Place of death and access to home care services: are certain patient groups at a disadvantage? Soc Sci Med 1998;47:565-79.

17. Davies JM, Sleeman KE, Leniz J, Wilson R, Higginson IJ, Verne J, et al. Socioeconomic position and use of healthcare in the last year of life: A systematic review and meta-analysis. PLoS Med 2019;16:e1002782.

18. Gallo WT, Baker MJ, Bradley EH. Factors associated with home versus institutional death among cancer patients in Connecticut. J Am Geriatr Soc 2001;49:771-7.

19. Johnson KS, Kuchibhatala M, Sloane RJ, Tanis D, Galanos AN, Tulsky JA. Ethnic differences in the place of death of elderly hospice enrollees. J Am Geriatr Soc 2005;53:2209-15.

20. Decker SL, Higginson IJ. A tale of two cities: factors affecting place of cancer death in London and New York. Eur J Public Health 2007; 17:285-90.

21. Thomas C, Morris SM, Clark D. Place of death: preferences among cancer patients and their carers. Soc Sci Med 2004;58: 2431-44.

22. Barclay JS, Kuchibhatla M, Tulsky JA, Johnson KS. Association of hospice patients' income and care level with place of death. JAMA Intern Med 2013;173:450-6.

23. Ministry of Health, Labour and Welfare. Dataset related to home care by region [Internet]. Tokyo, Japan: Ministry of Health, Labour and Welfare; 2019 [cited 2021 Mar 8]. Available from: https://www.mhlw.go.jp/stf/seisakunitsuite/bunya/000 0061944.html.

24. Ohta $\mathrm{H}$. Current conditions and issues for home care support clinics. Japan Med Assoc J 2015;58:6-9.

25. Portal Site of Official Statistics of Japan. Number of deaths and death rates by age [Internet]. Tokyo, Japan: Portal Site of Official Statistics of Japan; 2018 [cited 2021 Mar 8]. Available from: https://www.e-stat.go.jp/stat-search/file-download?statInfId $=000031883937 \&$ fileKind $=0$.

26. Ministry of Internal Affairs and Communications. Survey on municipal tax status [Internet]. Tokyo, Japan: Ministry of Internal Affairs and Communications; 2017 [cited 2021 Mar 8]. Available from: https://www.soumu.go.jp/main_sosiki/jichi zeisei/czaisei/czaisei_seido/ichiran09.html.

27. Abe K, Miyawaki A, Kobayashi Y, Watanabe T, Tamiya N. Place of death associated with types of long-term care services near the end-of-life for home-dwelling older people in Japan: a pooled cross-sectional study. BMC Palliat Care 2020;19:121.

28. Johnson EM. Physician-induced demand. Encycl Health Econ 2014;2014:77-82.

29. Kinjo K, Sairenji T, Koga H, Osugi Y, Yoshida S, Ichinose H, et al. Cost of physician-led home visit care (Zaitaku care) compared with hospital care at the end of life in Japan. BMC Health Serv Res 2017;17:40. 